Proceedings of the Seminar on the Social and Economic Effects of Earthquake Prediction, 12 October, 1977.

\title{
CENTRAL GOVERNMENT AND EARTHQUAKE PREDICTION
}

\author{
J. L. Roberts*
}

(Note: This is a background paper raising the problem of central government's obligations in the event that advice should be received by an appropriate Minister that reputable scientists believe there should be consideration of the consequences for public policy of earthquake prediction. It is not intended that it should be presented at the seminar but the author believes that these general reflections may be of some interest to the participants.)

It is accepted that government has a primary duty to protect citizens against the threat of disaster. States maintain defence forces to deter or resist aggression; most governments have commissioned emergency services to provide aid in the event of disaster; legislation exists for mobilisation of compensation for earthquake and war daruage act; the environmental control over such areas as the design of buildings to mitigate the consequences of disaster is a normal activity of politics.

The acknowledgement of this duty still leaves great problems unresolved. We can observe in the debate about the provision of resources for defence that there is deep disagreement about the extent to which other social objectives should be foregone to meet the cost of soldiers and their equipment. We may accept the need for building codes but when these force up costs or constrain freedom of design there is discontent. Above all, there is a tendency for emergency provision to fail from want of zeal. Thinking about the unthirkable is an ungrateful occupation. It seems that energetic provision of measures against disaster requires a degree of resolution not often found in political system except, of course, in the period immediately following the last disaster.

It seems to me that earthquakes are - or have been - a special case in this field of undoubted government obligation. Damaging earthquakes happen infrequently. In this, they differ from, say, fire or flood. They have a peculiarly alien quality. Unpredictable and frightening, the vast tectonic forces are beyond the understanding of the mass of citizens. Therefore there is little pressure to create and support more or less cheerfully elaborate services of the character which exist for, say, fire prevention and cure. Denied access by ignorance to the information of the seismologist and the engineer, the ordinary citizen hopes that the next earthquake will leave him untouched. If it does not, he expects in a vague way that the state will compensate him, or, of course, such heirs and successors as he may still possess after the shock. How many people who have

* Professor of Public Administration, School of Political Science and Public Administration, Victoria University of Wellington. taken very good care to insure their property are aware of their rights under the Earthquake and War Damage Act 1944?

This I believe summarises the position at present. But in the near future, we are promised - or threatened with a change in the nature of our attitude towards earthquakes. Scientific confidence in the evolving techniques of prediction is increasing. For society, a predicted specific earthquake is a very different proposition from the knowledge that a given area is subject to more or less regular severe seismic activity. Apprehension (confined to the neurotic in the first case) will become a universal intensifying element in public and private affairs generating pressures upon government to reassure the population that "adequate" steps to mitigate the effect of the earthquake when it occurs and to restore the fortunes of citizens in its aftermath.

We may say that the possibility of earthauake predictions imposes upon government two duties. The first is to seek and evaluate advice on the scientific reliability of predictions given the provision of sufficient resources to gather and interpret data. The second is to decide to do something or nothing about such findings.

It might be argued that the government should steadfastly ignore development of predictive techniques. Unfortunately for politicians this is impracticable. Science, and certainly geophysics and seismology is largely a public activity in this country. Those who come into possession of information affecting the security of life and property have no option but to pass that information on to the authorities who provide them with the resources for their work. In their turn, these authorities are obliged to consider the information soberly and thoroughly. In a free society it will be known that this exchange has taken place and a failure on either side of the contract will eventually lead to unacceptable political consequences for both groups of actors. Therefore we can be assured that the scientific evidence must lead to consideration of its political implications in the short or long term.

Before we can make assumptions about the political action that might follow this 
consideration, it is necessary to assess the demands on the politicians that might arise.

Let me reinforce the proposition that prediction involves different perceptions and therefore different policy options from the present situation in which it is generally recognized that New Zealand is a country in which earthquakes may occur at haphazard intervals in unknown locations. This has implications for general policy in scientific effort, codes of building practice, insurance arrangements, civil defence organisation location and provision of services. The possibility of an earthquake is thus one of a myriad of elements influencing the detail of broad policy.

Prediction alters the priorities. Once promulgated for a specific region an earthquake must become a dominant element in political choice increasing in influence until all social activity including government will be affected by the prediction and the outcome. In this situation, the demands upon the political structure can be categorised as follows:-

\section{(1) The preservation of social order and coherence -}

The most obvious difference between ordinary disaster and prediction disaster is the longer time span in which the links of social order are at risk. Commercial transactions, social undertakings, institutional functioning even family stability will all be disturbed as the variety of individual responses to the prediction takes effect. Government will no doubt be asked to show an example of coherence. (If the area of prediction were Wellington would they shift the location of government services and, if so which services? Should cabinet counter panic by remaining in the city?) The maintenance of public confidence by gestures and exhortation will be extremely difficult yet there is no doubt that government will be expected to make the effort.

Of course, the hehaviour of each individual will be altered by the specific policies announced by government but the general problem of morale will be similar to the problem arising in time of war.

\section{(2) Maintenance of Social Activity -}

The knowledge that an earthquake is imminent must have an effect on the level of all social action. It is likely that existing functions and services in the administrative, commercial and social sectors will be maintained. No doubt Government will be asked to help ensure this by offering indemnities and guarantees.

Depending upon the predicted scale of destruction this would no doubt be rational policy. What is not at all certain is that Government could or should induce private and public investors to continue with plans for new projects within the area of prediction. To some extent this would depend upon the nature of the project but no doubt partially completed structures would be particularly vulnerable. It seems certain that there would be a run down of investment. Given the unavoidable economic effect Government would be pressed to provide countervailing action such as assistance in raising the capacity of existing structure to resist earthquakes and the clearance of unredeemable earthquake risks.

\section{(3) Preservation of Property Values -}

It is logical to expect that an increasing number of citizens would leave the area of prediction as the prediction period shortened. Among those who stayed only a few would be disposed to risk resources in property investment. We may expect therefore that, unless countervailing measures are taken, the demand for property will fall steadily along with value. Will Government Valuation reflect the changed market conditions reducing the taxation base of local government? Will the increased risk involved in property dealings lead to rapidly rising interest rates as mortgagees seek to compensate for possible losses? What will happen to the liquidity of business houses as their financial status diminishes?

These problems will be put to Government. There are few guides to suggest how they may be attacked successfully.

\section{(4) Interaction between Area of Prediction and Rest of New Zealand -}

Much of the activity in any given centre is generated by its relationships with other areas. Some of this activity will be subject to review once a prediction is made. Trading relationships may become unattractive. potential disruption following the shock may persuade trades to shift out of operations as soon as a convenient opportunity presents itself. There will be resistance to public investment in transport facilities and other large scale services with a material as well as a local component.

The crucial difficulty will be resources. People in the area of prediction will no doubt consider it to be an obligation on the whole society to compensate for losses generated by the prediction. While there may be general acceptance that when (or if) the earthquake occurs the whole country should contribute equally to reconstruction, it is not at all certain that this will be so for the prediction costs.

\section{(5) Public Safety and Relief -}

It is normally difficult to sustain general citizen interest in civil defence. This will not be so in the area of prediction. Indeed we can expect the reverse with a growing public demand for expenditure on personnel and equipment to perform after the earthquake. Certainly, Government will be expected to provide leadership and materials even though manpower may be raised from the citenzry at large with perhaps a compulsory element as the earthquake moves closer.

Now suppose that these represent a reasonable selection of the demands upon Government. (We must keep in mind the point that we are discussing the first potential prediction or predictions to be made for New Zealand. Matters would become too complex to predict behaviour beyond that.) It seems to me that initial 
general courses of action are possible each with different consequences following upon a reputable scientific report that prediction is practicable within limits of accuracy that might call for public action. They are as follows:-

(1) No specific action.

(2) Official acknowledgement of report and assistance for more intensive scientific work.

(3) Official acknowledgement of report and encouragement of local countervailing measures in the area of prediction.

(4) Acceptance of official government responsibility to promulgate predictions and to take countervailing measures.

The factors which will influence the choice will be as follows:

(1) Quality of Scientific propositions

(2) Assessment of political consequences

(3) Assessment of costs of various alternatives.

(4) Public safety.

Let us then examine the situation to determine which would be the "best" action (i.e. most rational in the pursuit of public benefit) and which the most probable (.i.e. action considered to be most defensible against public criticism or most likely to secure public approval).

Let us assume that a scientist (or group of scientists) of good repute and adequately qualified in the relevant disciplines advises the Minister of science that prediction of the location, date and magnitude of earthquakes have been successfully made in other countries and that it may be possible to make predictions for New Zealand. No doubt this advice would be accompanied by some suggestions concerning government assistance to research and monitoring programmes.

Let us further assume that the advice contains evidence purporting to demonstrate that, employing the techniques outlined in his advice, the scientist (or group of scientists) predict that an earthquake of large magnitude is likely to occur within the next seven years and that the probable epicentre has been specifically located near a populous area. The Ministerrefers the advice to his Department and receives confirmation that the evidence has been accurately collected and analysed in accordance with hypotheses widely accepted within the scientific community and that the results justify the decision to raise the question of political consequences.

Given our four possible responses what reasoning is Government likely to bring to the choices before them.

\section{No Specific Actions}

\section{Reasoning}

(1) Any advice received is based on an hypothesis and must be insufficient to justify government action.

(2) The consequences of official public acknowledgement of prediction may be uncontroliable and it would be imprudent to risk them.

In this case, the dominant guide to action is the Government's judgement of political advantages to be gained from continued stability of expectations.

The problem is the uncertainty about public reaction to the information that the Government has refused to take action. In certain circumstances this would be an extremely difficult position to defend. The determining factors would be the specific area of prediction, the subsequent behaviour of the scientists and the chance of information falling into the hands of the media.

Official acknowledgement of advice and assistance to further scientific investigation Reasoning:

(1) As before the scientific advice is based on an hypothesis and is insufficient to justify government action.

(2) However, the Government acknowledges general responsibility to secure the "best" evidence for such action if possible and therefore accepts the case for increased official investment in earthquake prediction studies.

The problem here is the official acceptance of a level of credibility in the advice. No direct benefit will result to the public from scientific work yet the Government has, in effect, accepted advance warning that a catastrophe may occur. Since this will have to be announced and (given the parochial intensity of New zealand politics) will most certainly provoke reaction in the area of prediction, there is some doubt that a decision of this character could be sustained.

Acknowledgement of report and encouragement of local countervailing measures Reasoning:

(1) Government has a responsibility to assess the reliability of expert advice and to decide whether to lend its authority to the proposition that action should be taken as a result of the scientific findings.

(2) Government is not necessarily responsible for such action. (To take an analogy; the Government through its Ministry of Agriculture and Fisheries passes on to the farming community a great deal of information concerning scientific investigations carried out both in New Zealand and elsewhere. The Government does not necessarily consider that it has a responsibility to act as a result of these findings but rather prefers to leave it to individuals to take such action as the scientific result suggests.)

(3) Since the scientific advice applies most immediately to a particular area of prediction, the responsibility for action falls upon the citizens, private organisations and local authorities of that area.

(4) This can be considered to be rational since the cost of providing countervailing measures would represent an unacceptable charge on the country's general resources given the uncertainty of the prediction. of course, an actual disaster would evoke central government contribution; but to lock up resources on the basis of hypothetical probabilities goes beyond the demands that should be met by a prudent government. On the other hand, the inhabitants of an area of prediction have the right to decide for 
themselves the extent and cost of countervailing measures they may be prepared to make.

This reasoning suffers from the same defect as its predecessor. An official announcement of a potential future disaster must be a highly dramatic occasion in the area likely to be affected. Experience of politics in New Zealand suggests that when communities, groups or individuals feel that they are acting under specific disadvantages not suffered by others, they tend to feel that Government has a proper duty to redress the balance. Thus the selection of this alternative would most probably give rise to organised protest from powerful political interests in the area of prediction. Politicians would be forced to consider the effect of this upon their electrol chances.

Acceptance of official Government responsibility to promulgate predictions and to take countervailing measures

Reasoning:

(1) Although the scientific advice is based on hypothesis, safety of life and property is involved. This is a basic government responsibility that can only be discharged by open acknowledgement.

(2) Realistic political analysis will reveal that however uncertain the prediction, once it is made by reputable scientist(s) and adequately verified, the only defensible line of action for Government will be to assume responsibility for countervailing measures.

(3) The consequences of a prediction must be alarm, despondency and uncertainty with incalculable effects upon the order and prosperity of the area of prediction and to a lesser extent the rest of the country. positive authoritative countervailing measures are most readily supplied by Government.

(4) Although it can be argued that the Government should only become involved by cautious and limited commitment, calculated to match the growing efficiency of prediction techniques, in practice this is not possible since it will not be sufficient to deal with public attitudes. Given that earthquake prediction, by the time it reaches the assumed situation is a long term and recurring element in policy, there is no particular purpose served by hesitancy and indecision. Rather it is best to acknowledge from the beginning that prediction evokes a new and compelling form of government obligation.

(5) Bold positive policy is generally more attractive in political terms and is likely to enhance electoral fortunes.

This line of reasoning immediately raises a series of hard choices for Government. One aspect of the situation will complicate all countervailing policies. The very act of promulgating an earthquake prediction will involve economic and other costs for the inhabitants of the area of prediction quite apart from any losses suffered from actual earthquake damage. If Government accepts the responsibility of promulgation it will be difficult to resist the conclusion (however irrational) that Government should meet the resulting costs. Yet it is clear that specific calculation of the contribution of prediction to a downturn in, say, retail turnover, would be exceedingly difficult to make. Similarly, a fall in property values would certainly evoke a passionate claim for compensation. Should employment opportunities fall off, trade unions will doubtless press for action but given that a prediction period may be several years, over what time should the Government commit itself to help and up to what financial limit will it accept responsibility?

There are no easy answers to these questions. In my view it would be prudent to commission model studies now - possibly through an agency such as the New Zealand Institute of Economic Research to get a grasp of the dimensions of the commitment. We must hold on to the fact that predictions of earthquakes to a standard of reliability demanding policy response are very likely within a decade only by using sophisticated predictive techniques and considering a range of possible commitment can Government make a rational overall policy to deal with any specific prediction. The point is that this can be regarded now as necessary investment for future policy rather than speculative expenditure.

\section{THE NATURE OF POLITICAL RESPONSIBILITY}

One needs little reflection to realise that there will be few more difficult areas for the scientist as well as the Government once they are involved in the business of generating political responsibility based on earthquake predictions. For the forseeable future any prediction will be subject to a substantial area of doubt. Uncertainties abound yet once the prediction is made, there will be inevitable and possibly serious community and individual costs. Public emotions are bound to be stirred and reputations set at hazard. It seems to me that this is definitely against the public interest which requires that scientists should be able to publish their results without fear of obloquy because of the social consequences. On the other hand, Government will want political protection against any claim that they have abdicated to the scientists. It seems to me that there should be a specific, public and authoritative consultative system. Perhaps a panel of reputable scientists should review all predictions and assess their scientific merit. Once Government is persuaded that action is required, however, and promulgates the prediction it should be clear that all responsibility has passed from the scientist to the Government. Fraud apart, the scientist is dealing here only in probabilities and can not be fairly lumbered with the consequences of predictive success or failure.

\section{CONCLUSION}

Several points emerge. They are in order :-

(1) Predictive capacity is likely to be developed by New Zealand scientists.

(2) Once the prediction is made it will be impossible to keep it secret.

(3) The qualities of location and magnitude in the prediction alters the situation from any previous disaster policy field.

(4) The very act of prediction is a 
political act involving greater or lesser economic and social costs.

(5) It is difficult to see how these costs can be borne by any agency other than the Government. Experience tends to suggest that strong pressure will develop to force Government to assume this obligation.

(6) The ramifications of prediction costs and event costs are enormously complicated and sophisticated studies should be undertaken now to suggest means by which these costs may be rationally assessed.

(7) If Government does promulgate prediction it must be clear that it does so solely on its authority and that no other individual or group can be Iiable for the consequences of the information upon which Government acted. 